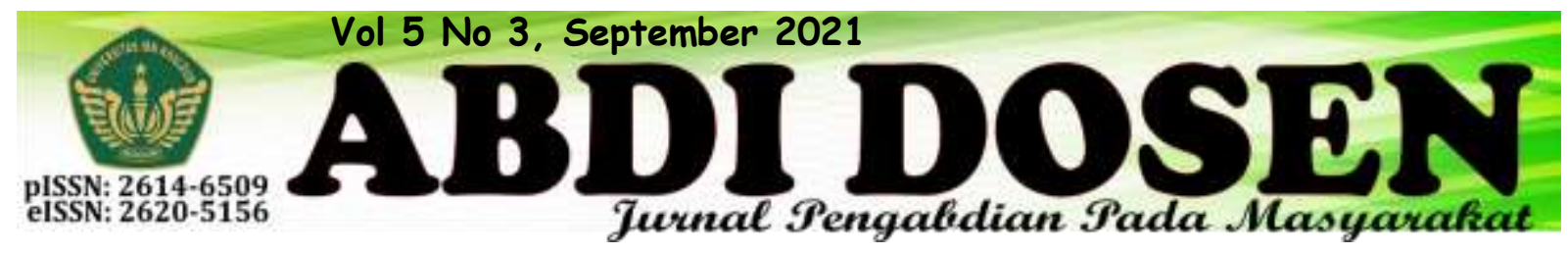

\title{
ANALISIS SOSIOPRAGMATIK TINDAK TUTUR CYBERBULLYING DI GRUP WHATSAPP PADA PESERTA DIDIK SEKOLAH DASAR KELAS 6
}

\author{
Eska Perdana Prasetya \\ eska@uika-bogor.ac.id \\ Fakultas Keguruan dan Ilmu Pendidikan, Universitas Ibn Khaldun
}

\begin{abstract}
ABSTRAK
Bullying itu adalah sesuatu perilaku kekerasan dengan adanya pemaksaan secara psikologis, sosial, dan akademik, jenis-jenis bullying itu bisa dikategorikan sebagai berikut: Bullying fisik, Bullying Lisan , Bullying Relasional Bullying Elektronik atau Cyberbullying . Cyberbulling itu adalah suatu fenomena bullying yang terjadi di media sosial dengan menggunakan teknologi informasi. Sembilan macam tipe cyberbullying: Flaming, Online harassment, Identity theft/impersonation, Outing, Exclusion/ostracism, Misinformation/Denigration, Cyber stalking, Happy slapping, and Sexting. Penelitian ini menggunakan metode kualitatif dengan observasi,wawancara dan elastase sebagai instrumennya. sosiopragmatik adalah studi tentang bentuk-bentuk ujaran dalam kaitannya dengan konteks sosial penutur, seperti jenis kelamin, karier, latar belakang budaya, etnis, konvensi, perilaku, atau gaya. Ciri karakteristik peserta didik anak SD sebagai berikut: minat terhadap kehidupan praktis sehari-hari, ingin tahu dan belajar, ada minat terhadap pelajaran khusus, berusaha menyelesaikan sendiri, memandang nilai rapor sebagai prestasi sekolah, dan gemar membentuk kelompok sebaya. Kalimat yang sering dilontarkan di cyber bullying adalah tentang hinaan fisik, atau body shaming, menyebarkan kebohongan tentang temannya, menuliskan yang memalukan/menyakitkan, dan suatu pengacaman. Namun faktor yang paling penting dalam cyberbullying adalah peran dari orangtua dan guru. Peran orangtua adalah epndamping dan pemberi nasehat ketika anaknya mendapat bullying. Sebagai guru harus mempunyai peran serta sebagai pengawas dan pemberi semangat.
\end{abstract}

Keywords: Analisis Sosiopragmatik, Tindak Tutur, Cyberbullying, Di Grup Whatsapp

\section{PENDAHULUAN}

Jika mendengar kata bullying di benak kita pasti akan tertuju pada satu kata yakni penindasan, ataupun seseorang yang disakiti oleh kata-kata atau tindakan yang terus menerus. (Piflkin, 2008) Bullying is a major issue that has a detrimental effect on students' social, psychological, and intellectual development. (Zakiyah et al., 2017) Bullying adalah suatu perilaku kekerasan dimana adanya unsur pemaksaan secara psikologis ataupun fisik terhadap seseorang atau sekelompok yang dianggap lemah. (Kartika et al., 2019) Efek Bullying tidak hanya pada korban saja, namun juga pada pelakunya. Dapat diartikan bullying itu adalah sesuatu perilaku kekerasan dengan adanya pemaksaan secara psikologis, sosial, dan akademik, namun 
faktor yang lebih parah lagi adalah efek dari bullying ini bisa ke pelaku bullyingnya dan bukan hanya pada korbannya saja.

Hoover dalam (Simbolon, 2012) Dua faktor penyebab bullying yaitu faktor internal (karakteristik kepribadian, kekerasan yang pernah dialami, dan sikap keluarga) dan eksternal. adalah: lingkungan, dan budaya. (Sufriani \& Sari, 2017) Ada beberapa faktor yang mempengaruhi bullying faktor individu, keluarga dan media, teman sebaya dan sekolah. Banyak faktor yang mempengaruhi pelaku ataupun korban bullying itu namun faktor yang sering muncul adalah faktor keluarga dan pelaku pernah menjadi korban bullying.

Bullying juga terdapat banyak tipe yang bisa untuk diteliti. (Antiri, 2016) The various types of bullying which were going on in the schools were; physical, social, verbal, cyber and psychological. (Cara Swit, 2019) Some examples of bullying are Physical bullying, Verbal bullying, Social and relational bullying, and Electronic or cyberbullying. (Kristensen \& Smith, 2003) Five ways of bullying are physical, verbal, indirect bullying, social exclusion, and attack on property.

Dari beberapa pernyataan diatas dapat disimpulkan bahwa jenis-jenis bullying itu bisa dikategorikan sebagai berikut:

a. Bullying fisik adalah jenis bullying yang melibatkan kontak fisik antar pelaku dan korban. Contohnya memukul, menendang, menampar, mencekik, menggigit, meludahi, dan menghancurkan barang-barang milik korban.

b. Bullying Lisan adalah jenis bullying yang melibatkan panca indera pendengaran, seperti memaki, menghina, menjuluki dengan kata negative, menuduh, memitnah dan gossip.

c. Bullying Relasional adalah jenis ini bullying yang melibatkan banyak orang ataupun kelompok. Fokus pada bullying ini menitikberatkan pada pengabaian, pengucilan, atau penghindaran pada korban.

\section{d. Bullying Elektronik atau} Cyberbullying adalah jenis bullying yang terbaru karena disebabkan kemajuan teknologi. Bullying ini terjadi di dunia maya seperti SMS, chatting, atau media sosial populer lainnya.

Dari keempat jenis bullying diatas, peneliti fokus terhadap satu jenis bullying yakni cyberbullying atau bullying di media elektronik. Seperti yang kita ketahui bersama sekarang ini kita memasuki era digital atau suatu era dengan kecepatan internet sebagai bagian dari hidup. (Wessels, 2017) Digital Age brought to our daily lives, the development of digital technology that came with this age. Banyak perubahan terjadi dari tatanan hidup di jaman ini termasuk fenomena cyberbullying.

(Utami, 2014) Cyberbullying adalah intimidasi berupa ejekan, ancaman ataupun hinaan yang terjadi di dunia maya terutama pada media sosial. (Rifauddin, 2016) cyberbullying adalah menyakiti orang lain dengan cara sengaja dan diulang- ulang dengan memakai teknologi internet. (Rahayu, 2012) Cyberbullying adalah perlakuan yang ditujukan untuk mempermalukan, menakut-nakuti, melukai, atau menyebabkan kerugian dengan menggunakan Teknologi Informasi. Jadi jelas cyberbulling itu adalah suatu fenomena bullying yang terjadi di media 
sosial dengan menggunakan teknologi informasi.

Di dalam cyberbullying itu sendiri terdapat beberapa tipe dari metode yang digunakan dari beberapa ahli. Newey \& Magson dalam (Rusyidi, 2020) sembilan macam tipe cyberbullying: Flaming, Online harassment, Identity theft/ impersonation, Outing, Exclusion/ ostracism, Misinformation/ Denigration, Cyber stalking, Happy slapping, and Sexting. (Slonje \& Smith, 2008) There are five types of cyber bullying; text message, email, phone call, and picture.

Tipe dari cyberbullying itu secara garis besar terdapat Sembilan tipe, tipe-tipe itu antara lain:

a. Flaming adalah pelecahan satu individu di ruang media sosial oleh beberapa orang dan lama kelamaan akan menjadi seperti mulanya api.

b. Online harassment adalah Pelecehan online didefinisikan sebagai pengiriman teks pesan atau email yang bersifat menyerang secara berulang-ulang

c. Identity theft/impersonation adalah berpura-pura menjadi orang lain dengan cara mengambil data dari seseorang dan menjadikan profil di akun seseorang.

d. Outing adalah memposting informasi yang bersifat pribadi yang berguna untuk merusak citra seseorang.

e. Exclusion adalah mengucilkan korban dari aktivitas sosial secara online dengan cara dihapus dari daftar pertemanan, disingkirkan dari grup.

f. Misinformation/Denigration adalah penyebarluasan informasi yang tidak benar dan membahayakan seseorang.

g. Cyberstalking adalah membuntuti korban secara online misalnya seorang murid menerima email dari seseorang yang tidak dikenal yang mengandung ancaman untuk melukai atau membunuh.

h. Happy slapping adalah tindakan yang berupa pemukulan atau pelecehan yang dilakukan seseorang dengan adanya perekeman video dan disebarluaskan.

i. Sexting adalah mengirimkan video atau foto vulgar yang bisa berupa editan yang disebarluaskan melalui media online.

Pada akhirnya dampak dari bullying juga sangat besar untuk korban dan si pelaku bullying itu sendiri. (Darmayanti et al., 2019) Dampak bullying berupa gangguan kesehatan mental. (Sukmawati et al., 2020) dampak dari cyberbullying adalah aspek psikologis, fisik, dan juga sosial. Cyberbullying yang dialami oleh mahasiswa menyebabkan yang bersangkutan mengalami depresi. (Aini \& Apriana, 2018) dampak dari cyberbullying yaitu bisa menimbulakn deprsesi pada korban. Dampak paling besar dari cyberbullying menyebabkan deprsesi yang bisa menyebabkan korbannya bunuh diri jika tidak diantisipasi.

Karakteristik peserta didik sekolah dasar pastinya berbeda dengan peserta didik yang berada diatasnya seperti peserta didik SMP dan SMA. Nasution dalam (Septianti \& Afiani, 2020) ciri karakteristik peserta didik anak SD sebagai berikut: minat terhadap kehidupan praktis sehari-hari, ingin tahu dan belajar, ada minat terhadap pelajaran khusus, berusaha menyelesaikan sendiri, memandang nilai rapor sebagai prestasi sekolah, dan gemar membentuk kelompok sebaya. Seifert dan Haffung dalam (Sugiyanto, 2005) Tiga jenis perkembangan usia anak SD yaitu fisik, kognitif dan psikologi. 
Dari karakteristik-karakteristik diatas hal menarik yang dapat dilihat dan sangat penting dalam perkembangan peserta didik kelas 6 pada khusunya adalah karakteristik kaingin tahuan dan belajar atas sesuatu yang baru. Hal ini tidak bisa dipungkiri dengan diberlakukan pembelajaran online pada masa pandemic seperti ini, dengan sebuah gadget mereka bisa membuka sebuah link

\section{METODOLOGI PENELITIAN}

Untuk penelitian ini, peneliti menggunakan metode kualitatif dengan observasi,wawancara dan elastase sebagai instrumennya. (Mills, 2016) Qualitative research is the collection, analysis, and interpretation of comprehensive narrative and visual (i.e., non-numerical) data to gain insights into a particular phenomenon of interest. (Creswell, 2018) Qualitative research is best suited to address a research problem in which you do not know the variables and need to explore. Penelitian kualitatif mengumpulkan, menganalisis, dan menafsirkan data naratif dan visual yang lengkap untuk memperoleh wawasan tentang fenomena tertentu dengan menarik (yaitu, non-numerik). Penelitian paling cocok untuk memecahkan topik penelitian yang tidak diketahui dan harus dieksplorasi.

Pendekatannya memakai sosiopragmatik. (Culpeper, 2009) The interaction of language and culture is referred to as sociopragmatics. (Manurung, 2010) Sosiopragmatik adalah studi tentang bentuk ujaran untuk memahami maksud penutur dalam kaitannya dengan konteks sosialnya, seperti jenis kelamin, karier, latar belakang budaya, etnis, konvensi, perilaku, atau gaya. (Mirzaei \& Roohani, 2012) The study of the links between communicative activity and power, social distance, imposition, and the social conditions and repercussions of what website. Dari sini perlunya peran serta orang tua murid dalam hal mengawasi dan memberikan edukasi kepada anak-anaknya untuk memilah mana yang boleh dilihat ataupun mana yang tidak boleh dilihat. Seperti yang kita ketahui pada umumnya anak kelas 6 sudah diberikan gadget oleh orangtuanya., ditambah kondisi seperti saat ini yaitu untuk proses pembelajaran online.

you do, when, and to whom is known as sociopragmatics.

Dapat disimpulkan bahwa sosiopragmatik adalah studi tentang bentukbentuk ujaran dalam kaitannya dengan konteks sosial penutur, seperti jenis kelamin, karier, latar belakang budaya, etnis, konvensi, perilaku, atau gaya.

Untuk penyedian data, peneliti mengambil data secara lisan melalui wawancara, penulis menyimak pertuturan murid yang ketika mereka menjelaskan tentang kejadian yang menyangkut tentang cyberbullying, mencatat data yang relevan sesuai dengan rumussan masalahpenulis menggunakan teknik-teknik sebagai berikut:

\section{Teknik observasi partisipasi}

Observasi yang digunakan oleh peneliti dalam melakukan penelitian langsung pada orang tua untuk mengamati perilaku berbicara mereka ketika menceritakan cyberbullying pada anak mereka.

\section{Teknik wawancara tak terstruktur}

Wawancara langsung dengan siswa digunakan untuk memperoleh data, yang tidak didahului atau disertai dengan serangkaian pertanyaan yang terperinci atau tepat. Peneliti ingin mendapatkan informasi sebanyak mungkin dari orangtua dengan cara yang paling alami dan layak. 


\section{Teknik elisitasi}

Suatu untuk Teknik memikat untuk memikat atau mengarahkan informan untuk memberikan data yang akurat. (Iqbal, 2014) Elicitation Techniques can be divided into two categories. 1. Direct approach: The direct method strives to improve comprehension of the issue at hand. 2 . Indirect approach: - An indirect approach is a means of obtaining information that is not readily available. Questionnaire and Document Analysis are two examples of this type of analysis. Berikut ini adalah langkahlangkah yang digunakan penulis untuk melakukan analisis data. Data dari rekaman pidato orang tua akan diubah menjadi

\section{HASIL DAN PEMBAHASAN}

Berikut pemaparan mengenai hasil penelitian tindak tutur pada siswa-siswa yang mendapatkan cyberbullying di grup whatsapp dan telegram.

\section{a. Tindak Tutur Asertif}

Meliputi menyatakan menerima/ menolak, mengusulkan, mengeluh, (Minarti et al., 2020) Bentuk tuturan asertif seperti: menyatakan, memberitahukan, menyarankan, membanggakan, mengeluh, menuntut, dan melaporkan. Pada kesempatan wawancara ini dilakukan dengan menggunakan voice note Whatapps. Pada bagian ini peneliti mecoba menggali informasi kepada siswa yang telah menjadi korban cyberbullying, didapatkan jawabanjawaban di bawah ini:

Penanya : "Bagaimana awal mula kamu masuk grup WA tersebut?"

Partispant 1 : “Awalnya saya di invite ke grup oleh teman sekelas. Nama grup itu adalah nama boyband di Korea." transkrip tertulis. Dengan bantuan pemahaman teori tindak tutur Searle dan Kreidler, data tersebut kemudian disajikan, diseleksi, dan ditelaah sesuai konteks untuk menentukan sifat dan fungsi tindak tutur. (Luthfiyanti, 2017) Tindak tutur asertif, direktif, ekspresif, komisif, deklaratif, dan validatif termasuk di antara lima jenis tindak tutur.

Partisipan nya adalah lima siswa yang mendapatkan cyber bullying di grup Whatsapps dan Telegram, namun pada saat wawancara siswa korban bullying itu selalu ditemani oleh orangtuanya. Hal ini dilakukan untuk menjaga perasaan dan traumatic dialami oleh partisipan.

Partisipant 2 : "Pada awalnya saya hanya diberitahukan oleh teman ada grup tentang pecinta ikan cupang, karena saya pecinta iakn cupang jadi saya join grup"

Partisipant 3 : "Dari teman ada informasi bahwa ada salah satu grup girlband asal korea"

Partisipant 4 : "saya tiba-tiba di invite ke grup dengan nama fans____ (salah satu klub sepakbola)dan saya pun tidak mencurigai apapun."

Partisipant 5 : "Grup yang saya ikuti adalah grup telegram yang nama grupnya adalah nama grup kelas"

\section{b. Tindak Tutur Ekspresif}

Menyatakan bahwa tindak tutur ekspresif adalah jenis tindak tutur yang menyatakan apa yang dirasakan penutur. (Murti et al., 2018) Beberapa bentuk tindak tutur ekspresif terdiri dari permintaan maaf, ungkapan kebahagiaan, tentang kesedihan, 
kekecewaan, kebanggaan, kekhawatiran, dan berterima kasih.

Penanya : : "Apa yang terjadi di grup itu?"

Partispant 1 : "Grup itu awal mulanya meng julidkan guru kelas, kemudian waktu itu aku Cuma bilang, jangan gitu dong...eh setelah itu aku diledek abis-abisan badan bau lah ga pernah gosok gigi lah"

Partisipant 2 : "Pada awalnya bahas kalau SMP mau dilanjutkan kemana, karena akum au lanjutkan ke (salah satu sekolah) malah aku diledek, dikiranya aku udah miskin dan ga punya modal masuk sekolah swasta favorit"

Partisipant 3 : "Saat itu berawal dari ada salah satu teman yang menyangka kalau saya melaporkan ke ayahnya jika suka bermain game online di warnet, saya sama sekali tidak tahu tentang hal itu, dan dia mengajak temanteman yang lain untuk mengejek saya di grup, julukan saya si pelapor."

Partisipant 4 : "Awal mula nya saya dituduh membawa mainan oleh seseorang di grup itu, Demi Allah saya tidak tahu tentang bola tersebut, tapi saya diancam akan digebugin"

Partisipant 5 : "Di grup itu mengejek teman di kelas lain habishabisan, saya mencoba untuk menetralisirkan namun saya yang dapat ledekan badan gendut dan lain-lain"

\section{c. Tindak Tutur Direktif}

Tindak tutur yang dilakukan penuturnya dengan maksud agar lawan tutur melakukan tindakan yang disebutkan di dalam tuturan itu. (Suryatin et al., n.d.) Cara komunikasi yang dimaksudkan pembicara untuk membujuk lawan bicaranya untuk bertindak dikenal sebagai tuturan direktif.

Penanya : "Apa yang kamu lakukan setelah mendapatkan perilaku tersebut?"

Partispant 1 : "Saya hanya diam di kamar dan bingung"

Partisipant 2 : "Mau bicara sama mamah tapi bingung"

Partisipant 3 : "Ga bisa ngapa-ngapin pak soalnya jadi bingung”

Partisipant 4 : "Sayajadi stress dan hanya bisa mukul-mukul meja di kamar"

Partisipant 5 : "Saya left dari grup itu tapi di invite lagi"

Pertanyaan Berikutnya

Penanya : "Jika saya ditanya oleh kalian apa yang harus dilakukan, jawabannya adalah berbicara dengan orangtua dan guru kalian, apakah sudah dilakukan?"

Partispant 1 : "sudah pak akhirnya"

Partisipant 2 : "Iya sudah ke orangtua"

Partisipant 3 : "Alhamdulillah sudah"

Partisipant 4 : "Iya waktu itu langsung curhat ke orangtua"

Partisipant 5 : "Beberapa hari berikutnya langsung curhat" 


\section{d. Tindak tutur komisif}

digunakan oleh penutur untuk membuat dirinya sendiri berkomitmen untuk melakukan tindakan tertentu di masa yang akan datang. Paina dalam (Liska Andrasari et al., 2017) ) Tindak tutur komisif adalah tindak tutur yang mengikat penutur untuk melaksanakan apa yang disebutkan dalam tuturan.

Penanya : "sekarang semua sudah terjadi dan kira-kira apakah kalian bisa berjanji untuk bisa move on untuk ke depannya?"

Partispant 1 : "Iya pak kejadian itu membuat saya harus lebih melek dan hati-hati dalam bergaul di dunia maya"

Partisipant 2 : "Kenangan di bully sungguh ga enak pak, tapi saya sekarang harus melupakan semuanya"

Partisipant 3 : "InsyaAllah sudah melupakan kejadian itu tapi kadang-kadang suka ingat dengan kejadian itu"

Partisipant 4 : "Kalau dingat suka sedih pak tapi saya InsyaAllah mencoba untuk melupakan itu sетиа"

Partisipant 5 : "InsyaAllah saya sudah melupakan semuanya, dan ga mau melakuakn itu sama orang lain”

\section{e. Tindak Tutur Deklaratif}

jenis tindak tutur yang mengubah dunia melalui ujaran mereka. (Eka et al., 2020) tindak tutur deklaratif berisi tentang tuturan memutuskan, membatalkan, melarang, mengizinkan, dan memberi maaf.

$\begin{aligned} \text { Penanya } & \text { "Apakah kamu bisa } \\ & \text { memberikan maaf pada } \\ & \text { teman-temanmu dan bisa } \\ & \text { melupakan itu semua untuk } \\ & \text { masa depan kalian semua?" }\end{aligned}$

Partispant 1 : "InsyaAllah bisa pak dan akan melupakan itu semua"

Partisipant 2 : "Harus bisa memaafkan pak walaupun susah, ini semua dilakukan untuk masa depan juga ya"

Partisipant 3 : "Kadang-kadang saya kesal mengingat itu seтиa namun harus bisa melupakan itu semua"

Partisipant 4 : "Memang susah melupakannya namun saya harus bisa dan tentu saja saya sudah memaafkan teman-teman yang berbuat itu"

Partisipant 5 : "Kata pa sutadz saya harus melupakan itu semua karena Allah aja maha pemaaf masa kita ga, walaupun susah untuk melupakannya"

Dari wawancara yang dilakukan melalui video call yang dilakukan satu persatu-satu participant dengan kaitannya lima aspek tindak tutur. Dapat sismpulkan bahwa cyberbullying bisa menimpa siapa saja yang dengan berbagai cara dan perlakuan. Awal mula cyberbullying ini terjadi karena dari sebuah grup WA dengan nama grupnya seperti klub sepakbola, grup musik boy band atau girl band.

Dilanjutkan dengan obrolan dan candaan yang menyerempet kepada meledek seorang guru, setelah itu anak yang merasa risih dan tidak mau untuk mengikuti ledekan dan candaan itu mulai melawan teman-temannya ataupun menolak untuk mengikuti candaan tersebut. Setelah itu 
barulah akan terjadi bully terhadap korban. Kalimat yang sering dilontarkan di cyber bullying adalah tentang hinaan fisik, atau body shaming, menyebarkan kebohongan tentang temannya, menuliskan yang memalukan/menyakitkan, dan suatu pengacaman.

Ada dua peran yang sangat berperan yaitu orangtua dan guru. Peran orangtua untuk anaknya terkena cyber bullying menurut peneliti adalah sarankan mereka untuk menghindari pelaku bullying,

\section{KESIMPULAN}

Bullying itu adalah sesuatu perilaku kekerasan dengan adanya pemaksaan secara psikologis, sosial, dan akademik. Cyberbulling itu adalah suatu fenomena bullying yang terjadi di media sosial dengan menggunakan teknologi informasi. Sembilan macam tipe cyberbullying: Flaming, Online harassment, Identity theft/ impersonation, Outing, Exclusion/ ostracism, Misinformation/ Denigration, Cyber stalking, Happy slapping, and Sexting. Kalimat yang sering dilontarkan di memberi tahu kepada mereka untuk menyingkir dan tidak terlibat di grup WA itu, tumbuhkan keyakinan mereka dan dorong mereka untuk memiliki persahabatan yang positif dengan sesama. Sedangkan peran guru terhadap anak yang korban bullying adalah orang tua sebagai panutan, pengendali tingkah laku anak, pihak yang bijak, pihak yang paling dekat, yang dapat dipercaya, dan sebagai pelindung anak.

cyber bullying adalah tentang hinaan fisik, atau body shaming, menyebarkan kebohongan tentang temannya, menuliskan yang memalukan/menyakitkan, dan suatu pengacaman. Namun faktor yang paling penting dalam cyberbullying adalah peran dari orangtua dan guru. Peran orangtua adalah epndamping dan pemberi nasehat ketika anaknya mendapat bullying. Sebagai guru harus mempunyai peran serta sebagai pengawas dan pemberi semangat. 


\section{DAFTAR PUSTAKA}

Aini, K., \& Apriana, R. (2018). DAMPAK CYBERBULLYING TERHADAP DEPRESI PADA MAHASISWA PRODI THE IMPACT OF CYBERBULLYING TO STUDENTS ' DEPRESSION OF NURSING PROGRAM HIGHER SCHOOL. Jurnal Keperawatan, 6(2), 91-97.

Antiri, K. O. (2016). Types of Bullying in the Senior High Schhools in Ghana. Journal of Education and Practice, 7(36), 131-138.

Cara Swit. (2019). What is bullying? https://Theeducationhub.Org.Nz/WpContent/Uploads/2020/05/What-IsBullying.Pdf. https://theeducationhub.org.nz/wpcontent/uploads/2020/05/What-isbullying.pdf

Creswell, J. W. (2018). Educational Research. In Pearson.

Culpeper, J. (2009). Historical sociopragmatics: An introduction. Journal of Historical Pragmatics, 10(2),179-186. https://doi.org/10.1075/jhp.10.2.02cu l

Darmayanti, K. K. H., Kurniawati, F., \& Situmorang, D. D. B. (2019). edagogia Jurnal Ilmu Pendidikan. Pedagogia: Jurnal Ilmu Pendidikan, 17(01),55-66.

https://doi.org/10.17509/pdgia.v17i1. 13980
Eka, D., Wardhana, C., Basuki, R., Magister, P., Bahasa, P., \& Bengkulu, U. (2020). Diksa: Pendidikan Bahasa dan Sastra Indonesia Tindak Tutur Ilokusi Asertif , Direktif, Ekspresif , Komisif , dan Deklaratif pada Program Gelar Wicara Mata Najwa. 6(1), 43-57.

Iqbal, T. (2014). Requirement Elicitation Technique: -A Review Paper. International Journal of Computer and Mathematical Sciences, 3(9), 16.

Kartika, K., Darmayanti, H., Kurniawati, F., Psikologi, F., Indonesia, U., Bullying, T., Bullying, T., \& Info, A. (2019). edagogia Jurnal Ilmu Pendidikan. 17(01),55-66. https://doi.org/10.17509/pdgia.v17il. $\underline{13980}$

Kristensen, S. M., \& Smith, P. K. (2003). The use of coping strategies by Danish children classed as bullies , victims , bully / victims , and not involved, in response to different ( hypothetical ) types of bullying. Scandinavian Journal of the Old Testament, 44(2), 479-488.

Liska Andrasari, Muzammil, \& Syahrani, A. (2017). TINDAK TUTUR KOMISIF DALAM DEBAT PILKADA KABUPATEN SAMBAS TAHUN 2015. Nhk 技研, 6(4), 1-10. https://doi.org/10.1145/3132847.313 $\underline{2886}$ 
Luthfiyanti, L. (2017). Jenis Dan Fungsi Tindak Tutur Guru Dan Siswa Dalam Proses Belajar-Mengajar Di Tkit Ukhuwah Banjarmasin (the Type and Function of Speech Acts Teachers and Students in Teaching and Learning in Tkit Ukhuwah Banjarmasin). Jurnal Bahasa, Sastra Dan Pembelajarannya, 6(1), 128. https://doi.org/10.20527/jbsp.v6i1.37 $\underline{45}$

Manurung, R. T. (2010). MODEL GAYA BERTUTUR PENGHUNI DI APARTEMEN BERSUBSIDI: SUATU KAJIAN SOSIOPRAGMATIK "ALIH KODE." Jurnal Sosioteknologi, 20(9), 923-933.

Mills, G. E. L. R. G. (2016). Educational REsEaRch Competencies for Analysis and Applications.

Minarti, W. A., Yusuf, C., \& Wijayanti, A. (2020). Tindak Tutur Asertif dan Formula Materi Ajar. Repitisi:Riset Pendidikan Bahasa Dan Sastra Indonesia, 3(2010), 1-12.

Mirzaei, A., \& Roohani, A. (2012). Exploring Pragmalinguistic and Sociopragmatic Variability in Speech Act Production of L2 Learners and Native Speakers Keywords. 4(3), 79102.
Murti, S., Nisai Muslihah, N., \& Permata Sari, I. (2018). Tindak Tutur Ekspresif dalam Film Kehormatan di Balik Kerudung Sutradara Tya Subiakto Satrio. Silampari Bisa: Jurnal Penelitian Pendidikan Bahasa Indonesia, Daerah, Dan Asing, 1(1), 17-32.

https://doi.org/10.31540/silamparibis a.v1i1.7

Piflkin, M. (2008). School Bullying: Definition, Types, Related Factors, and Strategies to Prevent Bullying Problems. EDUCATIONAL SCIENCES: THEORY\&PRACTICE This, 10(2), 555-562.

Rahayu, F. S. (2012). Cyberbullying | Cyberbullying. Jurnal Sistem Informasi, $\quad 8(1), \quad 22-31$. http://www.scopus.com/inward/recor d.url?eid=2-s2.0$\underline{54349105131 \& \text { partnerID }=\text { MN8TOA }}$ $\underline{R S}$

Rifauddin, M. (2016). Fenomena Cyberbullying pada Remaja. Khizanah Al-Hikmah: Jurnal Ilmu Perpustakaan, Informasi, Dan Kearsipan, 4(1), 35-44. https://doi.org/10.24252/kah.v4ila3

Rusyidi, B. (2020). Memahami Cyberbullying Di Kalangan Remaja. Jurnal Kolaborasi Resolusi Konflik, 2(2), 100.

https://doi.org/10.24198/jkrk.v2i2.29 $\underline{118}$ 
Septianti, N., \& Afiani, R. (2020). Pentingnya Memahami Karakteristik Siswa Sekolah Dasar di SDN Cikokol 2. As-Sabiqun, 2(1), 7-17. https://doi.org/10.36088/assabiqun.v $\underline{2 i 1.611}$

Simbolon, M. (2012). Perilaku Bullying pada Mahasiswa Berasrama. Jurnal Psikologi, 39(2), 233-243.

Slonje, R., \& Smith, P. K. (2008). Cyberbullying: Another main type of bullying?: Personality and Social Sciences. Scandinavian Journal of Psychology, 49(2), 147-154. https://doi.org/10.1111/j.14679450.2007.00611.x

Sufriani, \& Sari, E. P. (2017). FAKTOR YANG MEMPENGARUHI BULLYING PADA ANAK USIA SEKOLAH BANDA ACEH The Factors Affect Bullying on SchoolAge Children In Elementary Schools the Syiah Kuala Subdistrict In Banda Aceh. Idea Nursing Journal, VIII(3), $1-10$.
Sugiyanto. (2005). KARAKTERISTIK ANAK USIA SD. http://Staffnew.Uny.Ac.Id/.

Sukmawati, A., Puput, A., \& Kumala, B. (2020). Dampak cyberbullying pada remaja di media sosial. 1(1), 55-65.

Suryatin, E., Bahasa, B., Selatan, K., \& Selatan, K. (n.d.). TINDAK TUTUR DIREKTIF BAHASA INDONESIA PADA POSTER KESEHATAN Directive Act of Indonesian Language on Health Posters. 1.

Utami, Y. C. (2014). Cyberbullying di Kalangan Remaja. Jurnal Unair, 3(3), $1-10$.

Wessels, J. I. (2017). Introduction. Conflict and Society, 3(1), 125-129. https://doi.org/10.3167/arcs.2017.03 $\underline{0110}$

Zakiyah, E. Z., HUMAEDI, S., \& SANTOSO, M. B. (2017). Faktor yang mempengaruhi remaja dalam melakukan. Jurnal Penelitian \& PPM, 4(2), 324-330. 